\title{
Complex vesico-vaginal fistula repair with posterosuperior bladder flap
}

\author{
Enrique Rijo, Oscar Bielsa, J.A. Lorente, J.M. Gil-Vernet, Lluís Fumadó, Albert Francés, \\ Octavio Arango
}

Department of Urology, Hospital del Mar, Barcelona - Universitat Autonòma de Barcelona, Spain

\begin{abstract}
Introduction: Vesicovaginal fistulae (VVF) remain one of the most challenging problems in modern female urology.

VVF are classified as simple and complex. Complex fistulae are fistulae of large size (greater than or equal to $3 \mathrm{~cm}$ in diameter); those recurring after prior attempts at closure; those associated with a history of prior radiation therapy or with malignancy; those occurring in a compromised operative field owing to poor healing or host characteristics and those involving the trigone, bladder neck and/or urethra.

Materials and Methods: From November 1985 to September 2010, 58 cases of VVF were repaired at our institution with the Gil-Vernet technique, without the necessity of interposition of any autologous or heterologous material.

We present the case of a 44-year old woman with a previous history of cesarean, who presented with vaginal urine leakage after bladder injury with an initial attempt of primary closure during laparoscopic hysterectomy for uterine myoma.

This video describes the VVF repair using a autoplasty closure with posterosuperior vesical flap "The GilVernet technique.

Results: In $99.41 \%$ cases closure of the fistula was achieved at the first surgical attempt.

Conclusion: In our experience, the Gil-Vernet technique has been successful in most cases and we recommend this technique for repair of complex VVF.
\end{abstract}

Int Braz J Urol. 2011; 37 (Video \#6): 802_3

Available at: www.brazjurol.com.br/videos/november_december_2011/Rijo_802_803video.htm

\section{Correspondence address:}

Dr. Enrique Rijo

Universitat Autònoma de Barcelona

Department of Urology. Hospital del Mar

Passeig Maritim 25-29. Barcelona. Spain

Email: erijo@parcdesalutmar.cat 


\section{EDITORIAL COMMENT}

In the video by Rijo et al., the authors highlight a specific procedure (Gil-Vernet Technique) for the repair of a vesicovaginal fistula (VVF) within a single institution case series. VVF is a subtype of female urogenital fistula (UGF) in which an abnormal fistulous tract extends between the bladder and the vagina with the continuous involuntary discharge of urine into the vaginal vault. In addition to the potential medical sequelae of such fistulas, they often have a profound effect on the patient's emotional well-being and quality of life. Hence, VVF's pose a significant source of morbidity for affected women, highlighting the importance of managing this pathology using a highly successful and ideally minimally invasive technique. Techniques used to repair VVF have been well described within the peer reviewed scientific literature and the current video focuses on a contemporary approach. The authors submit a video pertaining to one of their cases treated in this fashion. The video is comprehensive and highlights the major pivotal points critical in a successful repair. This video nicely depicts how this surgical procedure can be conducted with successful correction of the underlying pathology.

Dr. Rafael E. Carrion Associate Professor of Urology Department of Urology USF Health College of Medicine

Tampa, Florida, USA E-mail:rcarrion@health.usf.edu 